\title{
PAPERS
}

\section{Inflammation of the gastro-oesophageal junction (carditis) in patients with symptomatic gastro-oesophageal reflux disease: a prospective study}

\author{
T Lembo, A F Ippoliti, C Ramers, W M Weinstein
}

\begin{abstract}
Background-Recent data have suggested that cardia biopsy specimens may be more reflective of gastro-oesophageal reflux disease (GORD) than squamous biopsy specimens.

Aims-To assess the distribution, severity, and types of mucosal injury in GORD.

Patients-Thirty patients with symptomatic GORD with no or minimal erosions. Methods-Biopsies were performed at the squamocolumnar junction ( $Z$-line) and 1-2 cm below the $Z$-line. Injury to the columnar mucosa was scored for inflammatory cells, epithelial cell abnormalities, and for the presence of intestinal metaplasia and Helicobacter pylori. A carditis score above 2 was considered positive (maximum score $=9$ ).

Results-Mean carditis scores and percentages of patients with a positive carditis score were higher in Z-line biopsy specimens containing both squamous and columnar mucosa than in those with just columnar mucosa or in specimens taken 1-2 cm below the Z-line. Carditis at the $\mathrm{Z}$-line was focal in $49 \%$ of the specimens and was always present adjacent to the squamous epithelium. Goblet cells were present more frequently in the specimens immediately at the $Z$-line than in those 1-2 cm below the Z-line. $H$ pylori was present in only four patients. The mean carditis scores of specimens $1-2 \mathrm{~cm}$ below the Z-line in these patients was significantly higher than in those patients without $H$ pylori.

Conclusions-Mucosal injury at the gastric cardia is highly localised to the region adjacent to the squamocolumnar junction in patients with GORD. Morphological studies of the cardia in GORD should focus on tissue samples that contain both squamous and columnar epithelium in order to obtain an accurate picture of the spectrum of injury.

(Gut 1999;45:484-488)
\end{abstract}

Keywords: gastro-oesophageal reflux disease; Helicobacter pylori; cardia; Z-line; squamous epithelium; columnar epithelium
Oesophageal mucosal biopsy is theoretically useful in patients with symptoms consistent with gastro-oesophageal reflux disease (GORD) who have normal appearing oesophageal mucosa during endoscopy. The sensitivity and specificity of oesophageal biopsy in this setting varies considerably for a variety of reasons. ${ }^{12}$ Twenty four hour $\mathrm{pH}$ monitoring is useful in some of these patients, although there is considerable variation in the sensitivity and specificity of this test also. ${ }^{3-5}$ Unfortunately, no gold standard test exists for diagnosing GORD in these patients.

The gastric cardia occupies an area a few centimetres immediately below the squamocolumnar junction (Z-line). It contains mucous type glands similar to those of the gastric antrum. In many instances it actually consists of mixed glands with both mucous glands and elements of the oxyntic mucosa with parietal and chief cells. Inflammation of this area of the stomach had largely been ignored until recently when preliminary studies suggested that biopsy specimens of this area may be more reflective of GORD than those from the distal oesophagus. ${ }^{6}$ Subsequent studies have produced differing results concerning the association of GORD with cardia injury, Helicobacter pylori infection, and intestinal metaplasia. ${ }^{7-11}$ Most of these studies have focused on cardia mucosa at various distances below the squamocolumnar junction (Z-line) rather than cardia mucosa at the Z-line. The cardia has also recently attracted attention because of the rapidly increasing incidence of cardia cancer $^{12-14}$ and the potential of detecting precursor lesion(s) in this area. ${ }^{15-17}$

This prospective study was designed to examine the spectrum of mucosal injury in the gastric cardia in patients with erosive or minimally erosive GORD. We hypothesised that cardia mucosa, if abnormal in GORD, should be maximally injured at the Z-line, the "battleground", rather than below it.

Abbreviations used in this paper: GORD, gastro-oesophageal reflux disease; LOS, lower oesophageal sphincter; LOSP, lower oesophageal resting pressure. 
Methods

PATIENTS

Thirty patients referred for evaluation of possible GORD symptoms (mean duration of 7.3

(2) years), namely heartburn, acid regurgitation, epigastric pain, or extraoesophageal manifestations were included. Only patients who had undergone upper endoscopy, oesophageal motility, and ambulatory $24 \mathrm{pH}$ monitoring were included. Patients with prior gastric or oesophageal surgery and patients with Barrett's oesophagus were excluded. In addition to characterising the symptoms in the patients' interviews, detailed information was obtained concerning the type, dose, and duration of antisecretory medication use and history of $H$ pylori treatment.

ENDOSCOPY AND HISTOLOGY

All endoscopies and biopsies were performed by one of two experienced endoscopists (WMW, AFI). Patients were included only if they had a normal appearing oesophagus or one thin linear erosion less than $1 \mathrm{~cm}$ long, and if the Z-line appeared to be contiguous with the lower oesophageal sphincter (LOS). All biopsy specimens were taken using a large cup pinch forceps biopsy, $8 \mathrm{~mm}$ open span (Microvasive, Boston Scientific Corporation).

In order to permit more accurate targeting, the biopsy specimens were obtained from within the stomach in the turnaround position. This was facilitated by inflating the stomach so the Z-line was flattened to permit en face targeting. If a hiatal hernia was present, two to three specimens were taken while attempting to position the opened cups of the forceps on the squamocolumnar junction. In this way, a sample of both mucosal types could be obtained in one biopsy specimen. If a hernia was absent or very small, the specimens were taken in the conventional end on position with the endoscope in the distal oesophagus. In addition to the Z-line samples, specimens for $H$ pylori were also taken 1-2 $\mathrm{cm}$ below the Z-line and from the stomach (prepyloric and mid body).

All biopsy specimens were oriented with mucosal side up, fixed in Bouin's solution, embedded in paraffin wax, and serially sectioned at $4 \mu \mathrm{m}$. Three slides, each with 10-15 sections were prepared: one was stained with haematoxylin and eosin (H\&E), a second was stained with $\mathrm{H} \& \mathrm{E}$-alcian blue, $\mathrm{pH} 2.5$ (to facilitate recognition of goblet cells and prevent their over diagnosis by rounded appearing cardia epithelial cells), and the third was stained with Giemsa stain to detect $H$ pylori.

The histological evaluation of the specimens was performed in a blinded manner by WMW. Biopsy sections were assessed for: (1) the type of epithelium (squamous, squamous and columnar, or columnar alone); (2) epithelial abnormalities in surface and pit epithelium (each scored 0-3); (3) inflammatory cell infiltrate densities for neutrophils/eosinophils and mononuclear cells (each scored 0-3); and (4) the presence of goblet cells, the presence of alcian blue positive columnar cells (columnar "blues"), and the presence of neutrophils/ eosinophils on the squamous side of those specimens containing both squamous and columnar epithelium. In specimens where the abnormalities were focal, an estimate was made of the percentage of biopsy length (in 10\% increments) that was abnormal.

A carditis score was calculated as follows: the sum of the neutrophil score (0-3) and the monocyte score (0-3), plus the greater of the surface or pit score for epithelial abnormalities. A carditis score greater than 2 was considered positive.

Biopsy specimens from the Z-line were divided for many of the analyses according to the type of epithelium they contained.

OESOPHAGEAL MANOMETRY AND 24 HOUR pH MONITORING

Oesophageal manometry was performed using a standard water perfused manometry system. ${ }^{18}$ Patients were considered to have a low lower oesophageal resting pressure (LOSP) if the mean amplitude in mid respiration was $\leqslant 10 \mathrm{~mm} \mathrm{Hg}$.

Ambulatory oesophageal 24 hour $\mathrm{pH}$ monitoring was performed using a single channel $\mathrm{pH}$ probe (Synectics) placed $5 \mathrm{~cm}$ above the manometrically measured LOS. Drugs known to affect acid secretion or motility were discontinued before $\mathrm{pH}$ monitoring as follows: 24 hours for $\mathrm{H}_{2}$ receptor antagonists and promotility agents and seven days for proton pump inhibitors. During $\mathrm{pH}$ monitoring each patient completed a standardised diary in which times and types of meals, periods of upright and supine body position, and time, duration, and type of symptoms were recorded. Data were evaluated by computer analysis. A subject was considered to have an abnormal $\mathrm{pH}$ recording if the total percentage reflux time (defined as a $\mathrm{pH}$ less than 4.0 ) was greater than $4.3 \%$. Johnson and DeMeester scores were also calculated. ${ }^{19}$

\section{STATISTICAL ANALYSIS}

Differences among groups were determined using $\chi^{2}$ and Fisher's exact tests. Bivariate correlations were determined using Spearman's non-parametric test. Variations around the mean are expressed as SEM. Probability values of less than 0.05 were considered significant.

\section{Results}

The 30 patients comprised 21 men and nine women (mean age 52.7 (15) years, range 29-72). Nine patients had not used any antisecretory medications for at least one month prior to upper endoscopy, eight patients used $\mathrm{H}_{2}$ blocker antagonists on a daily basis, and 13 patients used proton pump inhibitors on a daily basis for at least one month prior to endoscopy. Twenty seven patients had an intact oesophageal mucosa and three had a single thin, short erosion.

Fifty per cent (55/111) of the biopsy specimens obtained from the Z-line contained both squamous and columnar mucosa; $36 \%$ (40/111) contained only cardia mucosa; and $14 \%(16 / 111)$ contained only squamous mucosa. All but one patient had at least one 


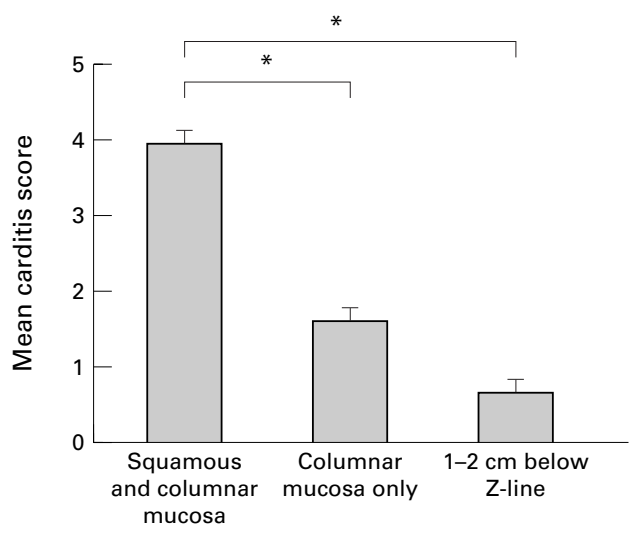

Figure 1 Mean carditis scores from biopsy specimens obtained in the gastric cardia.

specimen containing both squamous and columnar mucosa.

The Z-line specimens with squamous and columnar epithelium in continuity had significantly higher carditis scores than specimens with columnar lined mucosa only (3.8 (0.3) versus $1.7(0.2), \mathrm{p}<0.05)$. Specimens taken $1-2$ $\mathrm{cm}$ below the Z-line had lower carditis scores (0.5 (0.1), p<0.05) than either of the two Z-line biopsy groups (squamous and columnar epithelium in continuity and columnar lined mucosa only; fig 1). A positive carditis score was present in $96 \%$ of patients with Z-line specimens containing both types of epithelia (squamous and columnar epithelium in continuity) and in $67 \%$ of patients with Z-line specimens containing only cardia mucosa. Seventeen per cent of patients with biopsies targeted $1-2 \mathrm{~cm}$ below the $\mathrm{Z}$-line had a positive carditis score.

Carditis at the Z-line was focal in $48 \%$ (46/95) of specimens. In Z-line specimens with squamous and columnar epithelium in continuity the abnormalities were always greatest in the cardia mucosa adjacent to the squamous epithelium, even where the changes were focal. Where carditis did not involve the full length of a Z-line biopsy specimen, the mean percentage of involvement was 34 (5)\%.

More patients had goblet cells in Z-line biopsy specimens with squamous and columnar epithelium in continuity than either those with columnar lined mucosa only or those with specimens taken $1-2 \mathrm{~cm}$ below the Z-line (33\% versus $17 \%$ versus $4 \%$, p $<0.05$; table 1$)$. Alcian blue positive staining columnar cells (columnar "blues") were present in Z-line specimens with squamous and columnar epithelium in continuity in $37 \%$ of patients, in biopsy specimens with columnar lined mucosa only in $13 \%$ of patients, and in specimens $1-2 \mathrm{~cm}$ below the

Table 1 Relation of cardia to distance from histological squamocolumnar junction (Z-line)

\begin{tabular}{|c|c|c|c|c|}
\hline & \multirow[b]{2}{*}{$\begin{array}{l}1-2 \mathrm{~cm} \text { below } \\
Z \text {-line }(n=30)\end{array}$} & \multicolumn{2}{|l|}{ Z-line } & \multirow[b]{2}{*}{$p$ Value } \\
\hline & & $\begin{array}{l}\text { Columnar } \\
\text { mucosa alone } \\
(n=19)\end{array}$ & $\begin{array}{l}\text { Squamous }+ \\
\text { columnar } \\
\text { mucosa }(n=29)\end{array}$ & \\
\hline Positive carditis score (\% patients) & 14 & 56 & 96 & $<0.05$ \\
\hline Neutrophils within carditis (\% patients) & 16 & 31 & 63 & $<0.05$ \\
\hline Columnar "blues" (\% patients) & 4 & 13 & 37 & $<0.05$ \\
\hline Goblet cells (\% patients) & 4 & 17 & 33 & $<0.05$ \\
\hline
\end{tabular}

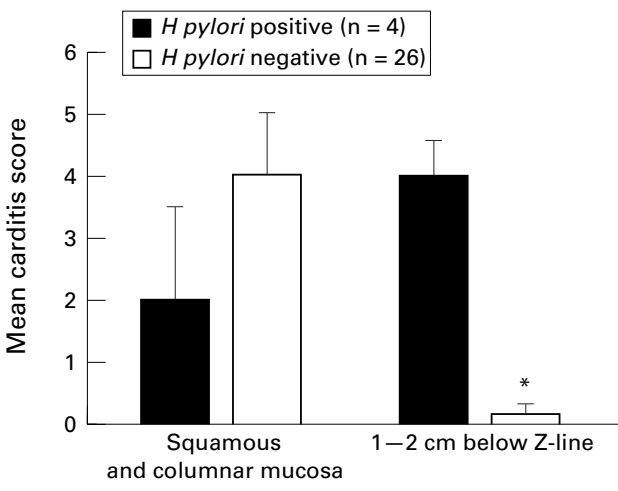

Figure 2 Relation of Helicobacter pylori status to mean carditis scores from biopsy specimens obtained at the Z-line, containing both squamous and columnar mucosa, and 1-2 cm below the $Z$-line. ${ }^{\star} p<0.05$.

Z-line in only $4 \%$ of patients $(\mathrm{p}<0.05)$. Mean carditis scores in $Z$-line specimens with squamous and columnar epithelium in continuity were similar in patients with goblet cells (3.3 $(0.5)$ and without goblet cells $(4.2(0.6) ; \mathrm{p}=0.2)$.

$H$ pylori gastritis was present in four $(13 \%)$ of the 30 patients. None of our patients reported receiving eradication therapy for $H$ pylori. The mean carditis scores were similar in the four patients with $H$ pylori and the 26 patients without $H$ pylori in Z-line biopsy specimens with squamous and columnar epithelium in continuity (fig 2) and in those with columnar lined mucosa only (results not shown). Those patients with $H$ pylori gastritis had significantly higher mean carditis scores $1-2 \mathrm{~cm}$ below the Z-line $(4.1(0.5))$ than did patients without $H$ pylori $(0.2(0.1) ; \mathrm{p}<0.05)$.

Fourteen patients had normal 24 hour $\mathrm{pH}$ studies (mean total time $\mathrm{pH}<4.0=2.4 \%$ ) and 16 had abnormal studies (mean total time $\mathrm{pH}$ $<4.0=13 \%$ ). Carditis scores were similar in the normal and abnormal $\mathrm{pH}$ groups in $\mathrm{Z}$-line biopsy specimens with squamous and columnar epithelium in continuity $(4.3(0.5)$ and 3.4 (0.5), respectively) and in specimens $1-2 \mathrm{~cm}$ below the Z-line (0.9 (0.5) and $0.6(0.3)$; table 2). In $Z$-line specimens with squamous and

Table 2 Histology in patients with normal and abnormal results on 24 hour $\mathrm{pH}$ monitoring

\begin{tabular}{lll}
\hline & \multicolumn{2}{l}{24 pH results } \\
\cline { 2 - 3 } Biopsy location & $\begin{array}{l}\text { Normal } \\
(n=14)\end{array}$ & $\begin{array}{l}\text { Abnormal } \\
(n=16)\end{array}$ \\
\hline Z-line & & \\
Columnar mucosa & & \\
$\quad$ Carditis score & $4.3(0.5)$ & $3.4(0.5)$ \\
$\quad$ Neutrophils & $57 \%$ & $18 \%$ \\
$\quad$ Mononuclear cells & $64 \%$ & $16 \%$ \\
$\quad$ Columnar "blues" & $38 \%$ & $44 \%$ \\
$\quad$ Goblet cells & $23 \%$ & $50 \%$ \\
$\quad$ Surface epithelial abnormalities & $14 \%$ & $9 \%$ \\
$\quad$ Pit epithelial abnormalities & $100 \%$ & $91 \%$ \\
Squamous mucosa & & \\
$\quad$ Neutrophils & $7 \%$ & $8 \%$ \\
$\quad$ Eosinophils & $21 \%$ & $16 \%$ \\
1-2 cm below Z-line & & \\
$\quad$ Carditis score & $0.9(0.5)$ & $0.6(0.3)$ \\
\hline
\end{tabular}

Carditis scores were similar in biopsy specimens with squamous and columnar mucosa and those $1-2 \mathrm{~cm}$ below the $\mathrm{Z}$-line in the normal and abnormal $\mathrm{pH}$ groups. The prevalence of neutrophils, eosinophils, mononuclear cells, goblet cells, alcian blue positive columnar cells (columnar "blues"), and epithelial changes was similar in patients with normal and abnormal 24 hour $\mathrm{pH}$ studies. 
Table 3 Mean carditis score and antisecretory medication use

\begin{tabular}{llll}
\hline & $\begin{array}{l}\text { None } \\
(n=9)\end{array}$ & $\begin{array}{l}H_{2} \text { receptor } \\
\text { antagonists } \\
(n=8)\end{array}$ & $\begin{array}{l}\text { PPIs } \\
(n=13)\end{array}$ \\
\hline Z-line & & & \\
$\quad$ Squamous + columnar & $3.6(0.3)$ & $4.0(0.6)$ & $4.1(0.9)$ \\
Columnar alone & $2.0(1.2)$ & $0.8(0.5)$ & $2.0(0.6)$ \\
1-2 cm below Z-line & $1.0(0.5)$ & $0.8(0.5)$ & $0.3(0.3)$ \\
\hline
\end{tabular}

No significant difference in mean carditis score was present in biopsy specimens at the Z-line, either with or without squamous mucosa present, or in specimens $1-2 \mathrm{~cm}$ below the $Z$-line.

PPI, proton pump inhibitor.

columnar epithelium in continuity the prevalence was similar in the normal and abnormal $\mathrm{pH}$ groups for neutrophils, mononuclear cells, goblets, columnar "blues", or surface or pit epithelial abnormalities. The prevalence of neutrophils and eosinophils in the squamous mucosa of the Z-line biopsy specimens with squamous and columnar epithelium in continuity was similar in patients with normal and abnormal 24 hour $\mathrm{pH}$ studies. There was also no significant correlation using Johnson and DeMeester scores and mean carditis scores in Z-line biopsy specimens with squamous and columnar epithelium in continuity or in specimens $1-2 \mathrm{~cm}$ below the Z-line.

Normal peristalsis was present in the body of the oesophagus in all patients during oesophageal manometry. Patients with low LOSP had similar mean carditis scores in Z-line biopsy specimens with squamous and columnar epithelium in continuity $(3.7(0.6))$ or in specimens $1-2 \mathrm{~cm}$ below the Z-line $(0.8(0.4))$ as did patients with normal LOSP (4.2 (0.5) and 0.8 (0.6), respectively).

Carditis scores, the components of the carditis score, and the other features assessed were the same in patients using antisecretory medications $\left(\mathrm{H}_{2}\right.$ receptor antagonists or proton pump inhibitors) and in patients not using antisecretory medications (table 3 ).

\section{Discussion}

The findings in this study help to explain the variation in results among studies that have examined the histology of the gastric cardia. We have found that cardia injury in GORD is localised to the immediate vicinity of the squamocolumnar junction and that sampling the mucosa 1-2 cm below this junction can result in a notable underestimation of the severity and type of mucosal abnormalities. This localisation was underscored by two other findings. Firstly, carditis scores were lower in those Z-line biopsy specimens that had only columnar epithelium. Secondly, when there was focal change in biopsy specimens with both squamous and columnar epithelia the mucosa adjacent to the squamocolumnar junction was abnormal while the mucosa at the end of the biopsy specimen was normal or only mildly abnormal.

We were disappointed that we were unable to obtain specimens uniformly with both squamous and columnar epithelium when the forceps was targeted at the Z-line. One reason is the position of the opened forceps. When the forceps opens in a plane that is at a more verti- cal angle in relation to the $\mathrm{Z}$-line it is easier to obtain both types of epithelium. However, when it opens in a plane that is more horizontal and thus more parallel to the Z-line there is less chance of obtaining both types of mucosa. To date we have been unable to find a way to rotate the endoscope in such a way that the forceps angle in relation to the $\mathrm{Z}$-line is substantially changed.

In our view there has been a rush to judgement in relation to the pathogenesis and importance of carditis. Different investigators are coming to different conclusions concerning carditis when both types of results may be true. We propose that carditis may be due to a number of different mechanisms: physiological reflux ("wear and tear"); gastro-oesophageal reflux; and $H$ pylori. The most common, in our opinion, is likely to be "wear and tear". By analogy, the squamous mucosa has been found in normal volunteers to exhibit the regenerative hyperplasia changes (basal cell hyperplasia and elongated dermal papillae) of reflux in the distal $2-3 \mathrm{~cm}$ of the oesophagus. These changes could represent the consequence of gastric contents "lapping at the shores of the oesophagus" in health. ${ }^{2}$ The same case can be made for carditis, perhaps even more so.

Carditis can logically be expected to be more severe or perhaps have unique features in GORD, either the erosive or non-erosive types. It is curious that for decades we have focused only on the squamous side of the battleground in GORD, and at a considerable distance from the "battle lines"- that is, $3 \mathrm{~cm}$ for biopsy and $5 \mathrm{~cm}$ for $\mathrm{pH}$ studies. Pathologists on the other hand have been aware of the severity of carditis in GORD for some time. The fact that we did not detect differences in mean carditis scores in patients with markers for more severe gastrooesophageal reflux (abnormal 24 hour $\mathrm{pH}$ tests and/or low LOSP) or in patients using antisecretory medications could be due to wear and tear injury to the cardia which occurs in almost all patients, thereby suppressing potential differences in patient groups.

The finding of goblet cells at a normally located Z-line may have implications in the pathogenesis of cardia cancer since it is likely that many if not all cardia cancers arise from either short segments of Barrett's oesophagus or from intestinal metaplasia of the cardia in the absence of overt Barrett's oesophagus. ${ }^{15} 16$ Other factors besides intestinal metaplasia seem to be important. The best example is that women with non-Barrett's GORD have a prevalence of goblet cells at the Z-line that notably exceeds their risk of either Barrett's oesophagus or cardia cancer. ${ }^{13}{ }^{20-26}$ The prevalence of goblet cells at normally located Z-lines in GORD varies considerably in different studies. ${ }^{20}{ }^{27-29}$ Based on our findings one important reason for this variation must be differences in biopsy location, because, in addition to carditis scores, the prevalence of goblet cells was strikingly reduced in biopsy specimens taken just $1-2 \mathrm{~cm}$ distal to the Z-line.

In addition to wear and tear and GORD, the other main cause of carditis is $H$ pylori. Not surprisingly, $H$ pylori gastritis often extends to 
the cardia, ${ }^{10}$ which is consistent with the findings in our study that patients with $H$ pylori had a greater carditis score than did patients without $H$ pylori. However, in our GORD population and in some recent studies from others, the prevalence of $\mathrm{H}$ pylori is one third or less, ${ }^{9}$ suggesting that it is neither the exclusive nor the primary contributor to cardia injury.

In conclusion, tissue sampling location is critical, independent of patient stratification, because carditis with or without intestinal metaplasia can be missed, or its severity grossly underestimated if the juxtasquamous mucosa is not represented in tissue specimens.

1 Schindlbeck NE, Wiebecke B, Klauser AG, et al. Diagnostic value of histology in non-erosive gastro-oesophageal reflux value of histology in non-ero
disease. Gut 1996;39:153-6.

2 Weinstein WM, Bogoch ER, Bowes KL. The normal human esophageal mucosa: a histological reappraisal. Gastroenteresophageal mucosa:
ology 1975;68:40-4

3 Cushieri A, Michel ME, Sadek S, et al. Computerized 24-hour ambulatory esophageal $\mathrm{pH}$ monitoring and esophagogastroduodenoscopy in the reflux patient. A comparative study. Ann Surg 1984;200:724-8

4 Masclee AA, de Best AC, de Graaf R, et al. Ambulatory 24-hour pH-metry in the diagnosis of gastroesophageal reflux disease. Determination of criteria and relation to endoscopy. Scand f Gastroenterol 1990;25:225-30.

5 Mattioli S, Pilotti V, Spangaro M, et al. Reliability of 24 hour home esophageal $\mathrm{pH}$ monitoring in diagnosis of gastroesophageal reflux. Dig Dis Sci 1989;34:71-8.

6 Oberg S, Peters JH, DeMeester TR, et al. Inflammation and specialized intestinal metaplasia of cardiac mucosa is a manifestation of gastroesophageal reflux disease. Ann Surg 1997:226:522 30.

7 Spechler SJ, Wang HH, Chen YY, et al. GERD versus $\mathrm{H}$. pylori infections as potential causes of inflammation in the pylori infections as potential causes of inflammation in the
gastric cardia [abstract]. Gastroenterology 1997;112:A297.

gastric cardia [abstract]. Gastroenterology 1997;112:A297.
Sherman R, Baig Z, Choudhry U, et al. The prevalence of Sherman R, Baig Z, Choudhry U, et al. The prevalence of
specialized columnar epithelium in patients with symptoms specialized columnar epithelium in patients with symptoms
and/or signs of gastroesophageal reflux. Gastrointest Endosc and/or signs of

9 Goldblum JR, Vicari JJ, Falk GW, et al. Inflammation and intestinal metaplasia of the gastric cardia: the role of gastroesophageal reflux and H. pylori infection. Gastroenterology 1998;114:633-9.

10 Genta RM, Huberman RM, Graham DY. The gastric cardia in Helicobacter pylori infection. Hum Pathol 1994;25:91519.

11 Antonioli DA, Goldman $\mathrm{H}$. Change in the type and location of gastric adenocarcinoma. Cancer 1982;50:775-81.
12 Blot WJ, Devesa SS, Kneller RW, et al. Rising incidence of adenocarcinoma of the esophagus and gastric cardia. FAMA 1991;265:1287-9.

13 Riddell RH. The biopsy diagnosis of gastroesophageal reflux disease, "carditis", and Barrett's esophagus, and sequelae of therapy. Am $\mathcal{F}$ Surg Pathol 1996;20:S31-50.

14 Schnell TG, Sontag SJ, Chejfed G. Adenocarcinomas arising in tongues of short segments of Barrett's esophagus. Dig Dis Sci 1992;37:137-43.

15 Cameron AJ, Lomboy CT, Pera M, et al. Adenocarcinoma of the esophagogastric junction and Barrett's esophagus. Gastroenterology 1995;109:1541-6.

16 Weinstein WM. Precursor lesions for cancer of the cardia. Gastrointest Endosc Clin North Am 1997;7:19-28.

17 Castell DO. Normal values in esophageal manometry. In: Esophageal motility testing. 2nd edn. Norwalk, Connecticut: Appleton and Lange, 1994

18 Johnson LF, DeMeester TR. Twenty-four hour $\mathrm{pH}$ monitoring of the distal esophagus. A quantitative measure of gastroesophageal reflux. Am $\mathcal{f}$ Gastroenterol 1974;62: 325-30.

19 Spechler SJ, Zeroogian JM, Antonioli DA, et al. Prevalence of metaplasia at the gastroesophageal junction. Lancet 1994;344:1533-6.

20 Johnston $\mathrm{MH}$, Hammond AS, Laskin W, et al. The prevalence and clinical characteristics of short segments of specialized intestinal metaplasia in the distal esophagus on routine endoscopy. Am f Gastroenterol 1996;91:1507-11.

21 Blot WJ, Devesa SS, Fraumeni JFJ. Rising incidence of adenocarcinoma of the esophagus and gastric cardia. fAMA 1993;270:1320

22 Meyers WC, Damiano RJ, Rotolo FS, et al. Adenocarcinoma of the stomach: changing patterns over the last 4 noma of the stomach: changing
decades. Ann Surg 1987;105:1-8.

23 Pera M, Cameron AJ, Trastek VF, et al. Increasing incidence of adenocarcinoma of the esophagus and esophagogastric junction Gastromterogy 1993;104:510-13.

24 Locke GR III, Talley NJ, Carpenter HA, et al. Changes in the site- and histology-specific incidence of gastric cancer during a 50 year period. Gastroenterology 1995;109:1750-6.

25 Wolf BC, Khettry U, Leonardi HK, et al. Benign lesions mimicking malignant tumors of the esophagus. Hum Pathol 1988;19:148-54.

26 Nandurkar S, Talley NJ, Martin CJ, et al. Short segment Barrett's oesophagus: prevalence, diagnosis and associations. Gut 1997;40:710-15.

27 Clark GWB, Ireland AP, Chandrasoma P, et al. Inflammation and metaplasia in the transitional epithelium of the gastroesophageal junction: a new marker for gastroesophaA66.

28 Morales TG, Sampliner RE, Bhattacharyya A. Intestinal metaplasia of the gastric cardia. Am $\mathcal{F}$ Gastroenterol 1997;92:414-18.

29 Hirota HK, Loughney TM, Laza DJ, et al. Specialized intestinal metaplasia, dysplasia, and cancer of the esophagus and esophagogastric junction: prevalence and clinical data. Gastroenterology 1999;116:277-85. 